Díaz, J.A. (2017). Los brincos que da la vida: la trayectoria armada de Roberto González Prieto 1948 1963. Revista de Sociología y Antropología: VIRAJES, 19 (1), 81-105. DOI: 10.17151/rasv.2017.19.1.5

\title{
LOS BRINCOS QUE DA LA VIDA: LA TRAYECTORIA ARMADA DE ROBERTO GONZÁLEZ PRIETO 1948 - 1963*
}

\section{JOSÉ ABELARDO DÍAZ JARAMILLO**}

Recibido: 12 de diciembre de 2016

Aprobado: 19 de enero de 2017

Artículo de Reflexión

\footnotetext{
* Artículo de reflexión que presenta resultados parciales de una investigación sobre la violencia política en Colombia, entre 1950 y 1970.

** Magíster en Historia, con estudios de Doctorado en Historia de la Universidad Nacional de Colombia. Profesor de dedicación exclusiva de la Corporación Universitaria del Meta y miembro del Grupo de Investigación Centro de Investigaciones Socio jurídicas Jorge Eliécer Gaitán. jodiz16@yahoo.com (ㄱ) ORCID: 0000-0002-8454-4296
} 


\title{
Resumen
}

El artículo hace un acercamiento a la vida de Roberto González Prieto entre 1948 y 1963. El objetivo es identificar los factores personales y sociales que motivaron su paso de la autodefensa campesina, en el contexto de la violencia bipartidista, a la lucha revolucionaria en tiempos del Frente Nacional. Para tal fin, se analizan diversos documentos, especialmente noticias de prensa, que hicieron referencia a González Prieto en esos años. Los resultados a los que se arriba establecen que la estigmatización de que fue objeto González Prieto, por su vinculación a la autodefensa campesina durante el periodo de La Violencia, incidió en la inclinación que éste tomó por el proselitismo armado radical durante los primeros momentos del Frente Nacional. La interpretación del caso González Prieto puede ser útil para pensar las implicaciones de la violencia simbólica como gestora de intolerancia, y, en últimas, de nuevas formas de violencias en la sociedad.

Palabras clave: Roberto González Prieto, violencia, guerrilla, MOEC 7 de Enero.

\section{THE TWISTS AND TURNS OF LIFE: THE ARMED PATH OF ROBERTO GONZALEZ PRIETO 1948 - 1963}

\begin{abstract}
The article approaches Roberto González Prieto's life between 1948 and 1963. The objective is to identify the personal and social factors that motivated his transition from the peasant armed self-defense in the context of the bipartisan violence, to the revolutionary fight in the "Frente Nacional" times. To this end, various documents, especially press news which referred to González Prieto, were analyzed. The results found establish that the stigmatization suffered by Gonzalez Prieto, due to his connection with the peasant armed self-defense during the period of "La Violencia," affected his inclination for radical armed proselytism during the beginning of the "Frente Nacional" times. The interpretation of the González Prieto case can be useful to think about the implications of symbolic violence as a manager of intolerance and, ultimately, of new forms of violence in society.
\end{abstract}

Key words: Roberto González Prieto, violence, guerrilla, MOEC January 7. 


\section{Presentación}

1 periodo de La Violencia constituye un capítulo amargo de la -1 historia nacional. No en vano, la referida confrontación civil arrojó como saldo una alta cifra de muertos (niños, mujeres y hombres), cuyos cuerpos quedaron esparcidos en los campos y aldeas del país, como resultado de los odios estimulados desde los púlpitos católicos y por la dirigencia de las dos agrupaciones partidistas, que mientras azuzaba la confrontación, vivía radicada en las ciudades o en el cómodo "autoexilio". Obligados por las dinámicas de una guerra que nunca fue declarada de manera oficial, muchos campesinos, especialmente de filiación liberal, se vieron obligados a crear mecanismos de defensa, a fin de poder sortear los ataques de que eran víctimas por parte de grupos armados, como los célebres "pájaros", la policía "chulavita", los "aplanchadores", los "penca ancha", entre otros.

En ese escenario de violencia el país conoció las atrocidades que, en nombre de ideologías en muchos casos poco comprendidas, fueron ejecutadas por grupos armados en diversos lugares de la geografía nacional. No obstante, pese a la descomposición política en jefes y miembros de estas bandas ${ }^{1}$, también se registró un hecho de interés que fue analizado hace ya varias décadas por Gonzalo Sánchez y Donny Meertens (1983): la mutación política de algunos integrantes de esos grupos armados, que pasaron de actuar por sentimientos asociados a sus simpatías partidistas, a reivindicar proyectos revolucionarios, ligados a contenidos nacionalistas y socialistas, producto de lecturas que hicieron -en algunos casos por interpuestas personas- de acontecimientos políticos de carácter internacional, como el proceso revolucionario chino y cubano.

Podría referirse, a modo de ejemplo, los casos de Pedro Antonio Marín (uno de los fundadores de las FARC), de Julio Guerra (quien hizo parte del Ejército Popular de Liberación), de José Ayala, Pedro Gordillo y Heliodoro Ochoa (quienes hicieron parte del Ejército de Liberación Nacional) y de Rosendo Colmenares, Eduardo Franco Isaza y Roberto González Prieto (miembros del Movimiento Obrero Estudiantil Campesino 7 de Enero) ${ }^{2}$. Como se sabe, cada uno de ellos actuó en o lideró autodefensas campesinas en una primera etapa de la violencia bipartidista, y luego, con el desarrollo y desenlace de la confrontación civil, terminó asumiendo posturas radicales, que en algunos casos los condujo a rechazar las amnistías y promesas de paz promovidas por el Estado.

\footnotetext{
${ }^{1}$ Lo cual recuerda la tesis de Eric Hobsbawm, quien señaló que muchos de los bandoleros dejan "de ser los defensores del pobre para convertirse en meros delincuentes o quedar a sueldo de los partidos políticos de los terratenientes y de los comerciantes" (Hobsbawm, 1983, p. 50).

${ }^{2}$ Una bibliografía básica sobre la vida de estos individuos aparece al final del texto.
} 
Tal fue la situación de Roberto González Prieto, de quien nos ocuparemos en este artículo, cuyo caso recrea la suerte de muchos campesinos del país entre finales de los años cuarenta y comienzos de los sesenta del siglo anterior. Al indagar por la vida de González Prieto entre 1948 y 1963, es inevitable revisar el papel del Estado, los partidos políticos y la prensa, en la construcción y extensión de un clima de intolerancia hacia grupos sociales que padecieron con intensidad la confrontación. Ese comportamiento se tradujo en la justificación y aplicación de formas de violencia física y simbólica hacia esos grupos. Tener presente esas consecuencias quizá pueda ser útil para pensar el momento que se vive en Colombia.

\section{En la autodefensa liberal}

Jorge Roberto González Prieto nació el 11 de marzo de 1922, en la vereda Coralito del municipio de Líbano (Tolima). De su familia se sabe poco. Sus padres fueron Joaquín Gonzalez ${ }^{3}$ y doña Benilda Prieto, ambos de origen campesino y simpatizantes del liberalismo, en una época en que la adscripción partidista era, en muchos casos, igual o más importante que la vida misma. Los primeros años de su vida Roberto González Prieto los pasó en el campo, junto a su familia, ayudando en las labores diarias. Años más tarde, González Prieto fue reclutado (sin contar con los 18 años cumplidos), siguiendo con una vieja costumbre que, sin ser oficial, estipulaba que los jóvenes del campo debían nutrir los contingentes del Ejercito Nacional.

Como soldado, González Prieto recibió adiestramiento en el Batallón Ayacucho de Manizales y, tiempo después, en el Batallón Guardia Presidencial (Sánchez y Meertens, 1983). Su permanencia en la institución castrense le permitió acceder a una libreta militar de primera clase (N²02501), expedida en el Distrito Militar N³2 de la Zona 3. Así, y sin saberlo, como también sucedió con otros individuos que se convertirían en jefes de grupos armados durante La Violencia (por ejemplo, Jacinto Cruz Usma, alias Sangrenegra), González Prieto recibió del Ejercito una formación en los asuntos de la milicia que será decisiva en su posterior desempeño como guerrillero.

Luego de concluida la experiencia en el cuartel, González regresó a la casa de su familia en Líbano, donde intentó forjar un lugar propio. No obstante, esa pretensión se vio interrumpida al cabo de un tiempo, por un

\footnotetext{
${ }^{3}$ Se afirma que el padre de González Prieto fue comunista y organizador de guerrillas en el Líbano en los años 20. No obstante, tal información no tiene apoyo documental que lo demuestre. Ver: http:// www.periodismosinfronteras.com/victimas-del-comunismo-memoria-historica-5.html
} 
acontecimiento ocurrido a cientos de kilómetros de donde se encontraba: el asesinato en Bogotá del caudillo liberal Jorge Eliécer Gaitán, hecho que, bien es sabido, desató con mayor intensidad la violencia partidista que se registraba en distintas zonas rurales del país, desde años atrás. Sorprendido por el acontecimiento, en poco tiempo González Prieto resultó envuelto en la espiral de violencia que aquel agudizó. El primer acto de violencia que González Prieto presenció fue la destrucción de la casa de sus padres, al igual que de los sembrados, por agentes de la policía afín al conservatismo. Era solo el principio. Enseguida se desató la persecución de los liberales de la zona, lo que provocó la huida de muchas familias. Otros tomaron la decisión de reaccionar para salvaguardarse: González Prieto y sus cuatro hermanos se armaron junto a otros campesinos de veredas vecinas, pudiendo así salvar sus vidas.

Esa primera experiencia de autodefensa, sin embargo, se fue extendiendo en el tiempo, y multiplicando territorialmente. A finales de 1949, González Prieto tomó la decisión de vincularse a un grupo de hombres dirigido por Agustín Bonilla Bocanegra -conocido con el sobrenombre de El Diablo- buscando contrarrestar, con más hombres y mejores recursos, las arremetidas del conservatismo sobre las bases liberales en el norte del Tolima. Pronto, al mostrar virtudes para los asuntos de la milicia, González Prieto se convirtió en el segundo comandante del grupo que se movía por los municipios de Venadillo, Líbano, Lérida, Alvarado y Armero.

El respeto del que ya era merecedor entre los suyos, se acrecentó con el sobrenombre que sus compañeros de armas le colocaron, y que daba razón de su destreza física y olfato guerrillero: Pedro Brincos. Mote que, por cierto, Roberto González no parecía reivindicar ${ }^{4}$ (un comportamiento que lo distinguió de otros jefes de grupos armados durante aquella época, que acudieron a sobrenombres llamativos para construir o acrecentar su imagen, como ocurrió con Desquite, Sangrenegra, Capitán Centella, Capitán Venganza, Chispas, entre otros) $)^{5}$, pero que sí fue resaltado por el Ejército y la prensa oficial de forma reiterada, cuando se referían a él, para asociarlo con actividades delictivas.

En 1952, en momentos en que era intensa la violencia política en distintas zonas del país, González Prieto decidió conformar un grupo armado propio, al que denominó La Línea. Buscó así deslindarse de su antiguo compañero, autor de prácticas que, a criterio de González, se

\footnotetext{
${ }^{4}$ En alguna oportunidad, un periodista le preguntó a Roberto González Prieto de dónde venía el mote de Pedro Brincos, a lo cual respondió: “Dizque porque brinco por cualquier parte, o 'chillo' por cualquier cosa (sic)" (La Republica, 16 de junio de 1959, p. 3).

${ }^{5}$ González Prieto manifestó haber trabajado en varias fincas ubicadas en el municipio de Calarcá ( $\mathrm{La}$ República, 16 de junio de 1959, p. 3).
} 
inscribían en el campo de la delincuencia. El comportamiento de González Prieto aquí ya advertía de una singularidad política que será recurrente en este periodo: lograr mantener como línea de acción la resistencia campesina ante la agresión del Estado y del conservatismo en el poder, y alejarse del bandolerismo en sus distintas expresiones. Esto explicaría por qué pronto se vio al nuevo agrupamiento de González Prieto gozar de la aceptación de los pobladores del Líbano, incluso de los hacendados más ricos e influyentes, de quienes recibió ayuda económica y material, al considerar el poder armado de González Prieto como un mecanismo de protección (Ramírez, 2004: 235).

Pocos meses después ocurrió un hecho político que incidió en la dinámica de la violencia en distintas regiones del país: el golpe militar de Gustavo Rojas Pinilla en 1954, y su interés manifiesto de convertir en política de Estado la desmovilización de los grupos campesinos armados que actuaban en el territorio nacional. El nuevo momento político obligó a González Prieto a adoptar "otra línea ideológica" y trazar "nuevas estrategias de lucha" (Ramírez, 2004, p. 236), pero sin renunciar a las armas, como lo pregonaba el gobierno de facto.

\section{En el Quindío}

Para mediados de 1957, y luego de que un paro patronal diera la última estocada al mandato del general Gustavo Rojas Pinilla, González Prieto se trasladó a Quinchía, lugar donde tenía contacto con líderes locales afines al liberalismo ${ }^{6}$. Lo hacía motivado por el deseo de iniciar un nuevo capítulo en su vida, alejado de las circunstancias que lo habían ligado a la violencia bipartidista reciente. La situación política inédita que se abrió paso con la salida del general Rojas Pinilla, y que estaba marcada por un discurso oficial proclive a la búsqueda de la paz y la tranquilidad en el país, fortaleció la decisión que tomó González Prieto de abandonar definitivamente las armas y comenzar una nueva vida junto a lo quedaba de su familia. Esta aspiración pareció redoblarse con la elección del presidente Alberto Lleras Camargo en 1958, quien continuó promoviendo un discurso sobre la paz y la necesidad de impulsar la amnistía y la rehabilitación como mecanismos para alcanzar la tranquilidad en el país.

\footnotetext{
${ }^{5}$ Roberto González Prieto prefirió emplear otros nombres, "de acuerdo con las circunstancias", como lo manifestó en alguna oportunidad: "Julio Calle", "Julio Ceballos", "Julio Hincapié", o "Capitán don Julio", fueron los más conocidos, con lo cual marcó una diferencia con los jefes armados que empleaban sobrenombres llamativos, como fue común en aquel periodo. Sobre el tema de los alias, sus significados y funciones en la historia de Colombia, puede consultarse la investigación de Orlando Villanueva Martínez, Guerrilleros y bandidos. Los alias y los apodos de la violencia en Colombia, Bogotá, Universidad Distrital Francisco José de Caldas, 2007.
} 
Es evidente que González Prieto vislumbró en la actitud del gobierno de Lleras Camargo una posibilidad de comenzar una nueva vida. Eso explica que él se dedicara a promover en 1957 el plebiscito a favor del Frente Nacional, y que se le viera organizando reuniones con campesinos en zonas rurales de Quinchía para hacer proselitismo a favor del nuevo pacto que se abría paso; y que, al año siguiente, hiciera política, abiertamente, con el Frente Liberal del Pueblo en el departamento de Caldas. Que la presencia y actuación de González fuera aceptada, también se puede explicar por el interés que tenían los gamonales y terratenientes de usufructuar su papel como mediador en un escenario bastante complejo, en donde aún había expresiones armadas ligadas al enfrentamiento bipartidista, y con conflictos sociales por el acceso a la tierra. Una persona como González Prieto, reconocida por su reciente protagonismo armado y convertido ahora en un promotor de paz, podría incidir en la construcción de un ambiente de tranquilidad que favoreciera a políticos locales y a propietarios de fincas. Él mismo así lo manifestó en una entrevista a un periódico conservador, cuando precisó que su labor en Quinchía había sido promover el respaldo al plebiscito, para lo cual realizó visitas a veredas "en comisión de paz": "Me pidieron en Quinchía que fuera a pacificar esa zona y en calidad de 'pacificador' llegué allí" (La República, 16 de junio de 1959, p. 3).

En el cumplimiento de esas labores González Prieto debió lidiar con líderes locales como Libardo Mora Toro ${ }^{7}$, que mostraban su inconformidad con el rumbo político que tomaba el país, y también con antiguos compañeros de armas como Medardo Trejo Ladino, alias Venganza ${ }^{8}$ y con Sargento García, quienes, al contrario de González Prieto, estaban decididos a continuar con las acciones armada. Del "Sargento García" dijo González Prieto: "Yo a lo último me enemisté con él... Yo quería la paz" (La República, 16 de junio de 1959, p. 3). Y agrega:

Posteriormente cité al alcalde de Quinchía, Gilberto Calvo y a varios sacerdotes a La Cumbre, en donde charlamos ampliamente sobre la situación existente en Quinchía. Ellos, precisamente, me autorizaron para que invitara a las gentes al trabajo honrado y para que votaran el plebiscito. Varias reuniones llevé a cabo y les hablé sobre el particular a los campesinos. (La República, 16 de junio de 1959, p. 3)

\footnotetext{
${ }_{7}$ Afirma González Prieto que cierta vez el "doctor Libardo Mora", quien se opuso al plebiscito por considerarlo un pacto de las oligarquías, le dijo acerca de quinientos campesinos que asistían a una reunión en Quinchía, que debían defenderse de las agresiones de que eran objeto. Ver La República (Bogotá, 16 de junio de 1959, p. 3). Libardo Mora Toro se convertirá, posteriormente, en líder del Ejército Popular de Liberación (EPL).

${ }^{8}$ Alias Venganza se había acogido a ciertos compromisos con una Comisión de Paz del gobierno, los cuales incumplió, prosiguiendo con su accionar delictivo. Fue abatido por tropas del ejército en junio de 1961. Una interpretación de su vida en Acevedo Tarazona (2004).
} 
Pese a las actuaciones a favor de la paz, que daban cuenta de un nuevo González Prieto, su suerte parecía no estar del todo en sus manos. En efecto, al revisar la imagen que de él construyó la prensa oficial (particularmente El Siglo y La Republica), se observa un marcado interés por desconocer los nuevos comportamientos de González Prieto, y por presentarlo como un individuo proclive a la violencia, en permanente deseo de ejecutar actos de sangre, y careciendo de cualquier concepción política. Por ejemplo, las labores ya comentadas de González Prieto a favor del plebiscito en lugares de Quindío, fueron mostradas por los diarios conservadores de una forma totalmente distinta. En realidad, sostenía dicha prensa, el verdadero interés de González Prieto había sido "organizar grupos de bandoleros y asumir el mando directo de estos", y los actos que impulsó como promotor de paz, escondían en realidad el propósito de invitar "a la revuelta" para "expulsar a los campesinos que no eran de confianza o adictos a sus ideas, con el único fin de apoderarse de sus tierras y ganados" (La República, 21 de abril de 1959, p. 3).

\section{La rehabilitación en el Frente Nacional}

“- ¿Qué opina de la amnistía? Muy buena... por lo menos se evita que lo sigan fregando a uno." Declaración de Roberto González Prieto en La Republica, junio 16 de 1959, p. 3.

Como ya se dijo, el gobierno de Alberto Lleras Camargo promovió dos figuras jurídicas para dar por terminada la violencia en el país ${ }^{9}$. La primera figura fue la amnistía, que consistía en la suspensión de la pena o del proceso judicial a aquellos individuos que hubieran cometido delitos políticos y se acogieran a ella. La segunda figura fue la rehabilitación, pensada como herramienta para la promoción de las zonas afectadas por la violencia, a través de la construcción de obras sociales (Afanador, 1993, pp. 57 y 58$)^{10}$.

\footnotetext{
9 El 27 de mayo de 1958 se constituyó la Comisión Nacional Investigadora de las Causas de la Violencia, la cual tuvo un importante papel en la interpretación de la confrontación política que había vivido el país recientemente. Como resultado de las investigaciones realizadas por la comisión, se crearon organismos como el Comité Ministerial de Orden Público, los Tribunales de Conciliación y la Oficina Nacional de Rehabilitación, con los cuales superar "los estragos de la barbarie" (Guzmán, Fals Borda y Umaña, 1963, p. 112).

${ }^{10}$ De la Comisión Especial de Rehabilitación, encargada de atender a las víctimas de la violencia, hacían parte los ministerios de gobierno, justicia, guerra, salud, educación, obras públicas y de agricultura. Según el Decreto 1718 de septiembre de 1958, que le dio origen, la comisión tenía como "tarea la preparación y ejecución del plan de rehabilitación de las zonas afectadas por la violencia" (Sánchez, 1985).
} 
A la primera figura se acogió González Prieto ${ }^{11}$, quien además inició los trámites para acceder a un préstamo de rehabilitación al que por ley podía acudir, según lo estipulado por el Estado respecto de aquellas personas que demostraran haber sido damnificadas de la violencia. Al invocar el derecho a un apoyo económico, se observa a González Prieto reclamando un sentido de justicia, el cual era ignorado o menospreciado por instituciones como la prensa, que de manera constante denigraba de él. Que González Prieto se asumía como una víctima de la violencia política, lo muestra la siguiente declaración que dio a un diario de lbagué:

Las pérdidas que he tenido durante los diez años de violencia son: cincuenta y siete mil pesos (\$57.000) en casas incendiadas, semovientes y cosechas; tres hermanos asesinados, más los niños y señora de uno de ellos, niños entre doce meses y diez años, que fueron masacrados y quemados con casa y todo, fuera de los diez años que llevo deambulando sin poderme estabilizar a trabajar (sic) tranquilo debido a la continua persecución tan injusta. (Tribuna, 24 de junio de 1959)

Por estas razones González Prieto reivindicó su condición de damnificado de la violencia, y su derecho a acceder a un préstamo económico del Estado:

En la finca de mis padres perdimos cincuenta y siete mil pesos. Era una buena finca de El Líbano y la destruyeron. Cuando cambiaron las cosas, nos consideramos damnificados y presentamos ante la oficina de rehabilitación los certificados correspondientes para obtener un préstamo, a fin de iniciar un negocio que nos diera para vivir. (Cromos, 20 de julio de 1959, p. 42)

Al considerar que la amnistía era una herramienta fundamental para la convivencia social, González Prieto acudió a un argumento de hondo significado político: "El primero que debe perdonar es el gobierno" (Cromos, 20 de julio de 1959, p. 42), queriendo indicar que el Estado tenía una cuota de responsabilidad en el origen de la violencia y, por lo tanto, le correspondía dar testimonios de reconciliación efectiva. Sin embargo, y contrario a lo que demandaba, vinieron para González Prieto momentos difíciles. El 26 de marzo de 1958 fue detenido por el Servicio de Inteligencia Colombiano (SIC) acusado de cometer diversos delitos, iniciándose un nuevo capítulo

\footnotetext{
${ }_{11}$ También lo hicieron Leopoldo García, General Peligro, Jesús María Oviedo General Mariachi, Hermógenes Vargas, General Vencedor y Germán Duzzan (sic), General Santander, entre otros (El Tiempo, 8 de julio de 1959, p. 7).
} 
en su vida que tendrá como rasgo principal la detención permanente. Lo anterior vino acompañado -o tal vez lo explique- de la estigmatización permanente de que fue objeto por la prensa oficial, que de paso convirtió la figura de la amnistía y la rehabilitación en objeto de batalla, y el caso de González Prieto en un hecho bochornoso que no debía ser tolerado. En esos términos, González Prieto fue presentado ante la sociedad como el "más temible delincuente" y el "tristemente célebre bandolero que organizó las cuadrillas de antisociales del Occidente de Caldas" (La República, 21 de abril de 1959, p. 3).

Meses después, en junio de 1958, González Prieto fue de nuevo capturado en Manizales por unidades del SIC, a pesar de que se había amnistiado, es decir, se había acogido voluntariamente a una política promovida por el Estado (Cromos, 20 de julio de 1959, p. 42). Buscado "desde mucho tiempo atrás" su detención, según informó la prensa, "mereció los más cálidos elogios" del Gobernador de Caldas, coronel Gerardo Ayerbe Chaux y del Jefe de la Seccional del SIC, teniente Carlos Guzmán Benítez (La República, 26 de junio de 1959, p. 10). Sin embargo, en marzo de 1959 fue puesto en libertad provisional por un juez, al no poder comprobar su responsabilidad en los hechos que le endilgaban. Una vez libre, y sin renunciar a la idea de tener una vida tranquila, González Prieto acudió de nuevo a la figura de la rehabilitación, y decidió tramitar un préstamo al que manifestaba tener derecho por su condición de damnificado de la violencia (Tribuna, 24 de junio de 1959). Parecía que las cosas esta vez lo favorecerían. La Oficina de Rehabilitación le otorgó diez mil pesos en efectivo, como anticipo de un monto de veinte mil que le fueron aprobados. Con esos recursos, González Prieto compró una finca cerca de Villavicencio, con el propósito de negociar con la venta de ganado. Por si fuera poco, el propio Ministro de Justicia, German Zea Hernández, previo dialogo con González Prieto, le manifestó que tramitaría para él una certificación de buena conducta. 


\section{La formula del día}

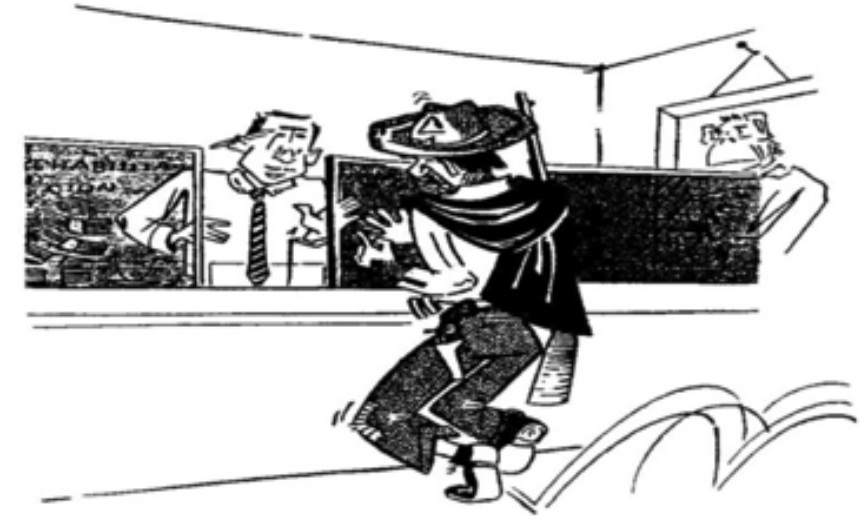

- Soy Pedro Brincos, he tomado parte en varios asaltos y ultimado a dos policías. Así que... Vengo por los diez mil que me restan.

- Pues... No se los podemos dar "por falta de pruebas".

Figura 1. La gran prensa mostró a González Prieto como un "peligroso bandido". Fuente: El Siglo (2 de agosto de 1959).

Sin embargo, en junio de 1959 González Prieto fue nuevamente detenido por agentes secretos en Pereira, "sindicado de numerosos delitos bárbaros en Quinchía y demás poblaciones del occidente de Caldas" ( $E l$ Tiempo, 13 de junio de 1959, p. 3). Según se informó, un juez de instrucción criminal de Ibagué lo requería por "tener parte en recientes hechos de violencia en el Tolima" y por haber participado en el asalto al ex gobernador del Tolima, Francisco González, ocurrido ocho años atrás (La República, 21 de abril de 1959, p. 3) $)^{12}$. Una vez detenido, González Prieto fue trasladado de las instalaciones del SIC de Manizales a la Penitenciaria de Ibagué: "La misma noche en que lo recluyeron le robaron la ruana", le manifestó a un periodista, (Cromos, 20 de julio de 1959, p. 42), tal vez queriendo resaltar que hasta de las cosas más simples González Prieto era despojado.

Obviamente, las acusaciones de que era objeto fueron desestimadas por González Prieto: "En realidad, yo hace tiempo que no vivo en este departamento (se refiere al Tolima, N.A.), aunque sí he estado de paso" (Cromos, 20 de julio de 1959, p. 42). Y a un periodista le dijo que entre marzo

\footnotetext{
${ }^{12}$ En otro lugar se informaba que González Prieto había sido detenido por participar en la ejecución de diez "indefensos campesinos de distintas filiaciones políticas" y el asalto a varias haciendas en el Tolima (Relator, 26 de abril de 1959, p. 1). Como se deduce, González Prieto tenía múltiples acusaciones por actos de violencia, cometidos en distintos lugares y en momentos diferentes.
} 
y junio (cuando quedó en libertad para luego ser de nuevo detenido, N.A.), estuvo en Bogotá tramitando un préstamo de rehabilitación (La República, 26 de junio de 1959, 10), y había viajado a Villavicencio para comprar una finca. Al insistir en las actividades a las que se había dedicado en los últimos meses, González Prieto pidió que se consultara al interventor nacional de rehabilitación, Julio José Fajardo, quien podría dar fe de la presencia de aquel "por estos días en Bogotá":

Con él me entreviste varias veces, y le dije que me ayudara pues lo había perdido todo. También conferencié con el doctor Jiménez, abogado de rehabilitación sobre el mismo problema.

La debilidad de las pruebas contra González Prieto obligaron al juez superior de Manizales a determinar que no había mérito para mantenerlo detenido (La República, 26 de junio de 1959, p. 10). Si bien Roberto González Prieto hizo parte de las autodefensas campesinas liberales y estableció contactos con agrupaciones que realizaron actos de clara estirpe delincuencial, resultaba difícil establecer su participación y responsabilidad en los hechos de sangre que le endilgaban. Había en él, en efecto un comportamiento que con el tiempo se reafirmará, cuando González Prieto intente cambiar la mentalidad de algunos de sus antiguos compañeros, imprimiendo a sus actos objetivos diferentes.

\section{El escándalo por el préstamo}

\section{"Los periódicos dicen lo que no es... pura basura". Declaraciones de González Prieto a La República (16 de junio de 1959, 3).}

La detención de González Prieto en junio de 1959 sirvió de motivo para que la prensa conservadora desatara un escándalo de grandes proporciones, a raíz de las políticas desplegadas por el gobierno para superar la violencia. El periódico El Colombiano, de Medellín, denunció el caso como "el símbolo macabro de una mentalidad de tolerancia" con el crimen, en tanto que, La Patria de Manizales manifestó que los dineros de la Oficina de Rehabilitación -la entidad creada con el fin de resolver las situaciones de emergencia a víctimas de la violencia y facilitar el tránsito a la vida pacífica de los ex-guerrilleros - no era más que un 'Fondo de el Crimen' (sic)". El semanario Estampa se sumó a las acusaciones, refiriéndose a la rehabilitación en términos similares: 
Desde hace un mes comenzaron a circular rumores de que algunos beneficiados con la rehabilitación eran bandoleros. Se dijo que dichos bandoleros (llamados 'ex guerrilleros' por la prensa de su partido) acogidos a la amnistía, habían recibido dineros de la rehabilitación, sin retirarse de su antigua vida delictiva. Los dos casos más comentados: 'Chispas' y 'Pedro Brincos', de quienes se han suministrado datos sobre sus 'actividades profesionales' así: A 'Chispas' se le considera el responsable de los asaltos de 'Las Palmitas' y 'San Antonio' (primer asalto, 23; segundo, 14 muertos conservadores); al segundo, con hojas de servicio por el estilo, se le estima como igualmente peligroso. La Patria de Manizales publicó un reportaje de 'Brincos' en el que afirmaba, franca, y sobre todo, frescamente, que le habían prestado diez mil pesos en la rehabilitación y que le debían diez mil más. (Estampa, 27 de junio de 1959, p. 5)

La República, que se opuso con firmeza a la amnistía y la rehabilitación promovida por el gobierno de Alberto Lleras Camargo, cuestionó con vehemencia el préstamo que fue otorgado a González Prieto. En un editorial titulado "Pedro Brincos y la 'Rehabilitación"', el diario conservador anotó:

La sociedad colombiana se ha enterado con horror y con indignación del tratamiento privilegiado, de la amnistía, los préstamos, los premios y las gabelas que les han venido otorgando las autoridades a los bandoleros más conspicuos que haya producido el país, desde el famoso Pedro Brincos hasta el Mico. Primero fue el decreto sobre amnistía y suspensión de los juicios que con tanto énfasis defendió el entusiasta Ministro de Justicia para derogarlo veinticuatro horas después. Más tarde la extraña práctica de la rehabilitación de los malhechores por medio de préstamos y donaciones que no han merecido siquiera los hombres de bien, y que es en nuestro concepto el más abundante estímulo que ha recibido la delincuencia en Colombia en todos los tiempos. En la sombría industria se han gastado, sin contar, los dineros del fisco, mientras gimen en la miseria y el desamparo las inocentes victimas del crimen. (La República, 23 de junio de 1959, p. 4)

El diario El Siglo no se quedó atrás en la campaña de denuncias, y pidió al Procurador General investigar al gobierno por el préstamo otorgado a González Prieto (El Siglo, 1 de agosto de 1959) ${ }^{13}$. La acusación de la prensa conservadora obligó al gobierno a pronunciarse sobre el tema. El director de la Comisión Ministerial de Rehabilitación, José Gómez Pinzón,

\footnotetext{
${ }^{13}$ Según informes oficiales, hasta mediados de junio de 1959 se habían realizado diez mil trece préstamos con un promedio de tres mil cuatrocientos pesos por beneficiado (El Tiempo, 18 de junio de 1959, p. 2).
} 
debió salir a dar explicaciones por las declaraciones de González Prieto a $\mathrm{La}$ Patria, en las que reconoció haber recibido un dinero:

Las palabras de 'Pedro Brincos', tal como aparecen en el reportaje original de 'La Patria', según las cuales 'ya por intermedio de Rehabilitación me dieron $\$ 20.000$ de los cuales he recibido $\$ 10.000$, o sea que todavía me deben otros $\$ 10.000$ que espero recibir muy pronto', demuestran una equivocación que no estoy en capacidad de atribuir ni al entrevistado, ni al redactor, pues de ellas se desprende que al primero se le hubieran obsequiado $\$ 10.000$, lo cual es completamente inexacto. Si el señor 'Pedro Brincos' recibió de cualquier entidad bancaria alguna suma, inferior a la que aparentemente solicitó -según el mismo reportaje- la obtuvo a título de préstamo y, en todo caso, en momentos en que se hallaba disfrutando de su libertad y no era reclamado por lo justicia ordinaria. (El Tiempo, 18 de junio de 1959, p. 2)

Como era apenas lógico, la prensa liberal salió en defensa de la política de rehabilitación del presidente Alberto Lleras Camargo. En editorial, El Tiempo fustigó a los críticos que no reconocían las bondades de la rehabilitación, como aquella de lograr que "millares de Pedros y Juanes", retornaran a los campos para "trabajar en paz":

Más de diez mil colombianos han sido ayudados por esta organización, que se formó a plena luz del día, con aplauso y respaldo de todo mundo, como que se encaminaba a la propia raíz del mal. La crítica sistemática no mira a los diez mil beneficiados sino a la mínima proporción de casos infortunados, previsibles en su número estadístico y perfectamente inevitables en que se ha perdido dinero o a caído en manos no santas.

¿Quién puede garantizar, en semejante número de casos y en las circunstancias bien conocidas, que no se comete un error? Salta a la vista la injusticia, por no decir la mala fe, de quienes se arrellanan cómodamente en sus butacas a insistir sobre Pedro Brincos cuando millares de Pedros y Juanes han regresado a sus trabajos, con dineros de la rehabilitación a trabajar en paz. (...) No hay castigo, pena de muerte, islas de reclusión que puedan hacer lo que producen los sistemas positivos, la ayuda mutua, el crédito, los frentes de trabajo. (El Tiempo, 18 de junio de 1959, p. 4) 
Para González Prieto era claro que la prensa distorsionaba los hechos que giraban en torno a su reciente pasado, respondiendo a propósitos mezquinos. Por ejemplo, al referirse a las actividades promovidas por él en Quinchía a favor del plebiscito, y su interés por la búsqueda de la paz, González Prieto señaló que la prensa se había dedicado a decir cosas distintas a lo que en verdad había sucedido. "Los periódicos dicen lo que no es... pura basura", sentenció en una entrevista. En el caso de las acusaciones de La Republica por el asunto del préstamo económico, González Prieto replicó:

El periódico La República al tener conocimiento de esto se ha venido con las suyas tratando de quitarme el derecho, pero yo quiero que la opinión pública se dé cuenta de que sí tengo derecho a la Rehabilitación por parte del Estado como colombiano que soy. Las pérdidas que he tenido durante los años de la violencia son: cincuenta y siete mil (\$57.000)". (La República, 26 de junio de 1959, 10)

\title{
5. Vinculación al MOEC 7 de Enero
}

\author{
"No sé qué es lo que quieren que haga." \\ Declaración de González Prieto a raíz de su detención \\ (El Tiempo, 28 de abril de 1961, p. 7).
}

En 1959 fue fundado en Bogotá el Movimiento Obrero Estudiantil Campesino 7 de Enero, el cual pregonó la lucha armada como recurso estratégico para la "toma del poder", como recién había sucedido en Cuba ${ }^{14}$. Desde un comienzo, el MOEC 7 de Enero desplegó esfuerzos para lograr acercar a antiguos combatientes del periodo de La Violencia, con el propósito de articularlos a los planes insurreccionales que pretendía adelantar. Esa intención quedó expresada en la Resolución Política que se aprobó en el primer congreso realizado en julio de 1960:

El primer congreso del MOEC expresa su más viva simpatía por el movimiento guerrillero de cualquier tendencia y espera agrupar a todos los hombres armados del campo bajo su comando revolucionario nacional, libre de bandolerismo y de los agentes de la reacción conservadora. De la re estructuración y nuevo contenido de la guerrilla campesina depende en altísima proporción el éxito de la defensa popular y el avance victorioso de una auténtica revolución

\footnotetext{
${ }^{14}$ Con el surgimiento del MOEC 7 de Enero, el mapa de la izquierda en Colombia se modifica al surgir nuevas agrupaciones: el Frente Unido de Acción Revolucionaria (FUAR), Acción Revolucionaria Colombiana (ARCO), Fuerzas Armadas de Liberación (FAL), Frente Unido del Pueblo (FUP), Movimiento Obrero Independiente y Revolucionario (MOIR), Ejército de Liberación Nacional (ELN), Ejército Popular de Liberación (EPL), etc.
} 
agraria que ponga fin a la angustiosa situación de las masas campesinas y al cerco inmisericorde de que son víctimas regiones enteras de los departamentos del Tolima, Huila, Cundinamarca, Valle, Caldas, Antioquia, Llanos Orientales y río Magdalena". (Resolución Política del Movimiento Obrero Estudiantil Campesino, 1960)

El llamado del MOEC 7 de Enero, del que tuvo conocimiento González Prieto, lo motivó a vincularse a la organización -al igual que lo hicieron Eduardo Franco Isaza y Rosendo Colmenares, excombatientes de las guerrillas del Llano-. En el MOEC 7 de Enero González Prieto fue recibido con respeto y admiración, al saberse de su trayectoria en la resistencia campesina posterior a la muerte de Gaitán. Si para sectores del bipartidismo González Prieto era expresión de muerte y violencia, para sectores radicalizados de la izquierda éste representaba la resistencia popular ante las agresiones de las elites dominantes. Varios militantes del nuevo movimiento político, procedentes del Tolima, conocían la trayectoria armada de González Prieto y sabían del distanciamiento que éste estableció en su momento con las prácticas bandoleras que promovieron los jefes de las cuadrillas ${ }^{15}$.

Sin duda, González Prieto debió tomar la decisión de acudir a las armas, otra vez, motivado por la frustración de no haber podido recomenzar su vida sin ser perseguido ni señalado. Las reiteradas detenciones y la estigmatización a las que se vio sometido, tuvieron un gran peso en esa decisión. Si bien había expresado en múltiples oportunidades su condición de damnificado de la violencia, y dio muestras de su disposición para promover la paz, González Prieto elaboró una lectura de su situación, en la que circulaba un argumento central que destacaba que el Estado y la sociedad en general, no le habían correspondido a él. De tal modo, el agravio moral del que era portador desde los tiempos de la violencia bipartidista, en lugar de desaparecer, permaneció latente e incluso se agudizó por las nuevas situaciones que debió afrontar. La decisión de volver a las armas, desde luego, debió ser difícil de tomar: otra vez la violencia aparecía en su camino. Pero, a diferencia de lo ocurrido años atrás, en esta ocasión las armas no serían un recurso empleado para proteger su vida, sino un instrumento para atacar un poder al que consideraba injusto. Se había configurado en él un sentimiento de injusticia que abrió las puertas para una insubordinación, tal y como lo analiza Barrington Moore (1989) en su estudio clásico sobre las bases sociales de la rebelión.

15 Es muy probable que el contacto de González Prieto con miembros del MOEC 7 de Enero, e incluso su vinculación a ese movimiento, se haya dado en la segunda mitad de 1959, cuando aquel se encontraba recluido en la Penitenciaria de Ibagué. En la cárcel González Prieto compartió celda con uno de los fundadores del movimiento, Robinson Jiménez, detenido desde hacía varios meses, quien le informó de los propósitos políticos y militares del movimiento, y debió animarlo a hacer parte del mismo. 


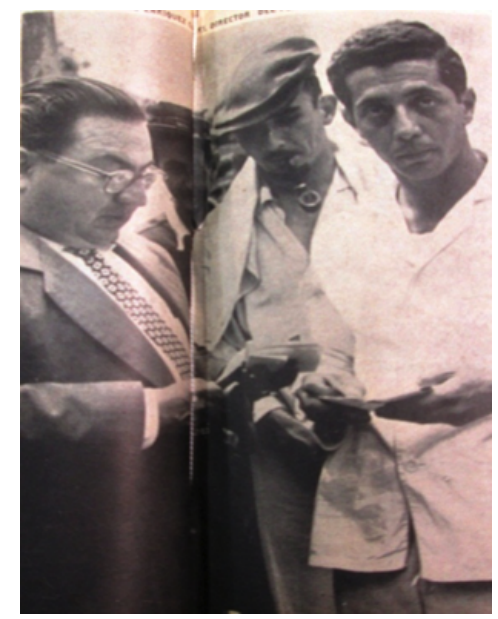

Figura 2. En el centro (con boina y pipa) Robinson Jiménez, miembro del MOEC 7 de Enero y compañero de celda de González Prieto en la Penitenciaría de Ibagué.

Fuente: Cromos, 1959, p. 41.

Luego de obtener su libertad, y ya vinculado al MOEC 7 de Enero, González Prieto participó en varios plenos y fue elegido para integrar la dirección nacional del movimiento, asumiendo responsabilidades de alto valor estratégico. En particular, se le asignó la misión de establecer contactos con antiguos guerrilleros para lograr su incorporación al movimiento, y promover procesos organizativos en ciertas regiones, con el fin de constituir frentes guerrilleros.

A finales de 1961, el MOEC 7 de Enero intentó crear una zona de operaciones guerrilleras en la región de Urabá. Era la segunda vez que el movimiento pretendía implantar una fuerza armada, para lo cual escogió a González Prieto como uno de los responsables. Tan sólo unos meses atrás Antonio Larrota González (tal vez el dirigente más destacado de esa organización) había sido asesinado en montañas de Tacueyó, en el departamento del Cauca, cuando realizaba labores tendientes al mismo fin.

Es altamente probable que en el momento de ser detenido por agentes del DAS en Medellín en abril de 1961, González Prieto se encontrara realizando labores ligadas a la preparación de la misión en Urabá, que al final resultó en otro fracaso, luego de que el grupo rebelde fuera delatado y perseguido por tropas del ejército. La mayor parte del destacamento fue neutralizado en el primer y único enfrentamiento que entabló con las tropas, logrando sólo salir con vida González Prieto junto a otro miembro de la organización (Díaz Jaramillo, 2012). 
El tropiezo no significó para González Prieto, ni para el MOEC 7 de Enero, un replanteamiento del proceder armado. De hecho, González Prieto buscó posteriormente, atendiendo la antigua directriz de la organización, establecer contactos con antiguos compañeros del periodo de la violencia bipartidista, para incorporarlos a la organización. Lo intentó con José William Aranguren, Desquite y con Jacinto Cruz Usma, Sangrenegra, con quienes había convivido por los lados del Líbano años atrás (Ramírez, 2004, p. 239), y aún continuaban operando y al mando de hombres. A Desquite le envió una carta firmada el 28 de enero de 1962 desde Bogotá, en la cual le hacia la invitación para que se uniera a la organización de izquierda. En la misiva González Prieto acudió a argumentos políticos, que difícilmente podían estar en las mentes de individuos como Desquite:

Desde tiempo atrás -escribe González Prieto- yo vengo luchando aisladamente sin obtener ningún resultado efectivo. Son muchas las regiones del país donde estuve organizando (sic) que pueden ser testigos. Ahora, no sólo por experiencia personal sino por todos los luchadores de Colombia, como el mundo entero, me he convencido de que será estéril la lucha hasta tanto no sea puramente de carácter nacional en donde se agrupen bajo una dirección colectiva, todos los movimientos políticos de izquierda, grupos armados y todo cuanto esté luchando y quiera luchar, por la liberación de nuestro pueblo colombiano (...). (Moncada, 1963, p. 215)

\section{Y agregaba:}

En forma despectiva tú hablas de jefes, hay unos movimientos revolucionarios que quieren organizar la revolución con especialidad el MOEC, que está más adentrado y directamente se encuentra organizando la lucha armada con algunos resultados sobre el particular... en (sic) este movimiento puede contar usted que no hay jefes: hay dirección colectiva, y como tenemos la perfecta convicción de que la revolución no la puede hacer sino el pueblo en su conjunto, por tal razón es que recurrimos al contacto con los hombres que hasta ahora se han destacado por su lucha para con todos éstos formar la dirección colectiva de unidad revolucionaria. Esta es una condición, una necesidad de la revolución para que pueda llegar a su feliz término. El deseo del movimiento es que tú participes, o cualquiera del de esa (sic) en unas charlas que pronto se van a realizar en esta ciudad. (Moncada, 1963, p. 215) 


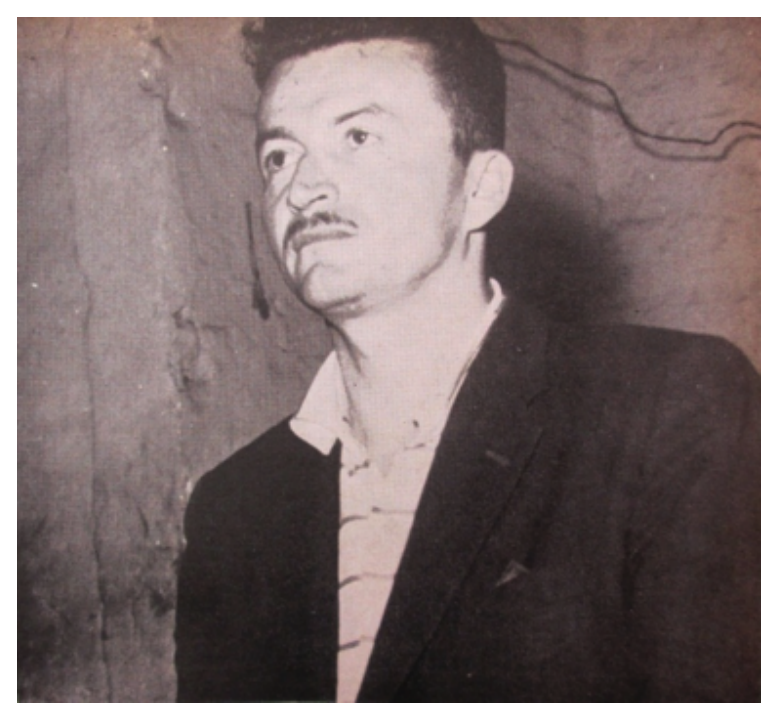

Figura 3. Roberto González Prieto recluido en la Penitenciaria de Ibagué.

Fuente: Cromos, 20 de julio de 1959, p. 40.

Para persuadir a Desquite, González Prieto le hizo saber que el MOEC 7 de Enero lo tenía en una estima especial, y que de unirse a la organización, ocuparía una responsabilidad dentro de la misma:

Te puedo decir que el movimiento te tiene en cuenta y con mucha estima, se ha dado cuenta que tus esfuerzos no son vanos, la lucha incansable que tú has llevado durante tanto tiempo, pese a las condiciones de aislamiento en que tú has venido luchando frente al concierto internacional; yo que soy el que conozco, de los de aquí, un poco más de sus actividades, he tratado de presionar para que no se deje sóla (sic) esa región y para que tu hagas parte de un organismo nacional. Yo he insistido que en los organismos u organismo nacional que se encargue de la dirección militar, deben estar hombres que tengan algunos conocimientos prácticos sobre el particular: claro que como tú dices, los hombres que integren la dirección deben estar en la montaña, es decir, al lado de los hombres de armas esto ya está decidido. Por esto es que te digo que me gusta que tú estés en las charlas que se van a realizar próximamente, pues de ahí saldrá lo concreto a escala nacional (...)" (Moncada, 1963, p. 215) 
Tiempo después, el 23 de octubre de 1962, Desquite se entrevistó con González Prieto, a quien no solo le manifestó su desinterés por la propuesta que éste le había hecho, sino además le advirtió que debía abandonar la región. Igual suerte tuvo con Sangrenegra, a quien no le vinieron bien las condiciones que establecía González Prieto, como las relacionadas con el buen trato a los campesinos "a través de prácticas aparentemente tan intrascendentes como el pago de la comida en los sitios que solían frecuentar en sus desplazamientos", o con la adopción de medidas en el funcionamiento y estructura organizativa "que se reflejaran en una nueva postura ideológica frente a la lucha en que estaban empeñados" (Sánchez, 1983, p. 128) ${ }^{16}$.

\section{El final}

"Los campesinos son los llamados a iniciar la lucha armada." De una circular atribuida a Roberto González Prieto" (El Tiempo, 17 de septiembre de 1963, p. 3).

Luego del fracaso militar en Urabá y de la infructuosa labor de acercamiento de jefes armados de la violencia anterior, González Prieto decidió regresar al norte del Tolima, con el propósito de impulsar un nuevo centro de operaciones guerrilleras. El lugar escogido era ampliamente conocido por él, lo cual se convertía en un factor favorable para sus propósitos. Para la nueva empresa armada contó con el acompañamiento de Ricardo Otero, un barranquillero que había renunciado a sus estudios universitarios en Bogotá, y que contaba con una breve militancia de izquierda, primero en el Movimiento Socialista Colombiano, y luego en el Frente Unido de Acción Revolucionaria (FUAR).

Las actividades de González Prieto en la zona se centraron en la “adoctrinación (sic), unificación y coordinación de las guerrillas, apoyo al trabajador rural e incitación a la insurrección armada" (Guzmán, 1964, p. 334). Que fuera así resalta la importancia que otorgaba González Prieto a la concientización política de las bases en las que pretendía encontrar apoyo. Un manifiesto que circuló en la región, elaborado por el propio González Prieto, da cuenta de ese interés y de la dimensión política que articulaba su actuación:

\footnotetext{
${ }^{16}$ Otros bandoleros intentaron, por su propia cuenta, acercarse al MOEC 7 de Enero, como ocurrió con Arcadio Ruiz Restrepo, alias Cenizas, en 1962 (Delgado, 2011, p. 140).
} 
Nuestra guerrilla agrupa en un solo frente de lucha a todas las organizaciones como ligas campesinas, sindicatos de obreros y empleados, etc., para que luchen por liberar a nuestro pueblo colombiano: campesinos, obreros, estudiantes y profesionales sin tener en cuenta su color político, sexo o religión.

Entendemos que los trabajadores solo podrán tomar el poder político liquidando la gran muralla contra la cual siempre se han estrellado las fuerzas armadas de represión. Este objetivo se logrará constituyendo el ejército nacional de liberación cuya forma más simple son las guerrillas revolucionarias las cuales operarán en estrecha colaboración de los trabajadores de las ciudades. Los campesinos son los llamados a iniciar la insurrección armada.

Toda esta grave situación, tendrá que cambiar cuando los trabajadores conquisten sus derechos por medio de las armas. Ya tenemos un ejemplo en la América Latina. (El Tiempo, 17 de septiembre de 1963, p. 3)

Sorprende del escrito la presencia de razonamientos que dan cuenta de un nivel de politización, claramente inclinado hacia la izquierda radical. La reivindicación de la lucha armada, en clave de un proceso de liberación nacional, y la formulación estratégica de un frente de lucha multiclasista, demuestran la existencia de una concepción política totalmente diferente a la que reivindicaba González Prieto en épocas pasadas, adquirida en su paso por las distintas estancias de la organización de la que hacía parte. En un boletín que editaron González Prieto y Otero, denominado Cordillera Central, del cual se publicaron varios números, expresaron su visión de la política nacional, acudiendo a expresiones como explotación, y en la cual los "enemigos del pueblo" aparecían identificados, como las compañías norteamericanas y los ricos. En el análisis elaborado por González Prieto se observa una lectura estructural de la sociedad y del poder:

De nuevo comenzamos a observar en nuestros campos y ciudades las frecuentes incursiones de los politiqueros de todos los pelajes prometiéndole a los campesinos y a todo el pueblo 'el cielo y la tierra' para llevarlo como cabras al 'abrevadero' a las elecciones con el fin de legalizar en el Totalitario Parlamento la explotación, el hambre, la penetración de ejércitos mercenarios dirigidos por misiones norteamericanas, y el saqueo de nuestros recursos naturales como el petróleo, el platino, etc., por parte de compañías norteamericanas. Los campesinos y todo nuestro pueblo debe (sic) entender que las vías pacíficas para lograr la toma del poder político no dejan de ser meras ilusiones. Los ricos están sólidamente unidos en el Frente Nacional al cual están vinculados por el privilegio los llamados disidentes 
de 'Izquierda'; además, los hacendados de todos los partidos se encuentran organizados en grandes Asociaciones: de agricultores, cafeteros, arroceros, cañeros, etc., y de igual manera los grandes industriales y comerciantes. Mientras las minorías ricas acumulan y malgastan la riqueza, los campesinos sienten cómo su jornal sólo les alcanza para tomarse con su familia 'el agua dulce' ya que el salario percibido por el jornalero y el arrendatario sólo les alcanza para adquirir el atado de panela; a la vez, los medianos y pequeños finqueros van aceleradamente hacia la ruina". (Guzmán Campos, 1964, p. 334)

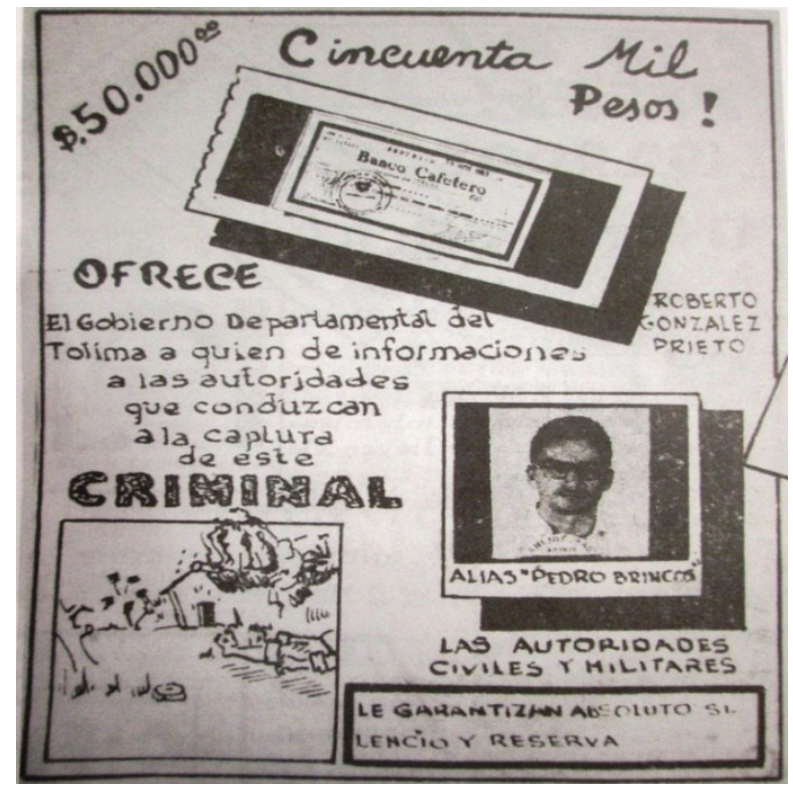

Figura 4. Propaganda que ofrece recompensa a quien informe el paradero de Pedro Brincos.

Fuente: Prado Delgado, 2010, p. 165.

Por los planteamientos consignados en este tipo de manifiestos, y por la trayectoria de líder armado de que era portador, González Prieto se convirtió en una prioridad militar para el gobierno. En el propio Congreso de la República se suscitaron debates en torno a él y su "extrema peligrosidad"; de él incluso se dijo que había recibido entrenamiento militar en Cuba y se le había visto uniformado en el norte del Tolima, pretendiendo unificar a los "bandoleros, para ponerlos al servicio de la revolución comunista de signo internacional" (Pabón, 1963, p. 55). 
Estas representaciones de González Prieto tuvieron como efecto que el Estado dedicase calculados movimientos para neutralizarlo, a tal punto que por él se ofrecieron recompensas económicas y se desplegó, bajo el mando del coronel José Joaquín Matallana, una unidad militar especial -el célebre Batallón Colombia- con el propósito de eliminarlo, hecho que ocurrió en septiembre de 1963, cerca de la población de Lérida.

\section{Conclusión}

La vida de Roberto González Prieto después del 9 abril de 1948 estuvo signada por injusticias que se enmarcaron en un contexto de múltiples violencias, sobresaliendo especialmente la que promovieron instituciones afines al establecimiento (prensa, partidos, funcionarios). Estos sectores nunca renunciaron a tratar a González Prieto como un antisocial y bandolero, en una evidente estrategia para justificar su eliminación física y desconocer cualquier motivo de orden político en su actuación. De hecho, el proceder de González Prieto y su papel como actor armado en una confrontación a la que se vio abocado a participar y de la que fue, en parte, víctima, fue definida -simple y llanamente- como carrera delictiva. Desde la propia perspectiva de González Prieto, había desde luego una interpretación diferente de su comportamiento en aquel periodo:

Yo no fui propiamente guerrillero con las armas en la mano. Eso sí, organicé masas de campesinos para que se defendieran de los ataques de la policía y de las guerrillas conservadoras. Y esas masas lucharon por sus vidas y sus pequeños bienes. (Cromos, 20 de julio de 1959, p. 42)

Como se demostró, el tratamiento dado a González Prieto por la prensa oficial, incidió de forma notable en su decisión de inclinarse a la radicalización política. Al respecto, se advirtió que la decisión de vincularse al MOEC 7 de Enero debió ser una respuesta a la persecución de que fue objeto, a pesar de haber manifestado en múltiples oportunidades su deseo de iniciar una nueva vida y acogerse a la amnistía ofrecida por el Estado. Las reiteradas detenciones por parte de los organismos de seguridad, y los señalamientos de la prensa oficial, efectivamente, impidieron que González Prieto pudiera retomar su vida de campesino. 
Teniendo presente las tesis de Hobsbawm sobre las formas del bandidismo, el caso de González Prieto ilustra el paso de un bandolerismo social a un estado en el que las formas de protesta se transformaron en cruzadas revolucionarias, configuradas a partir de la idea de igualdad. González Prieto, en efecto, se adaptó "a las nuevas formas de la lucha por la causa de los campesinos", lo que impidió que terminara convertido en un simple delincuente o quedara "a sueldo de los partidos políticos de los terratenientes y de los comerciantes" (Hobsbawm, 1983, pp. 44, 50). Que haya sucedido así, se debió, sin duda, a la presencia de un sentimiento de injusticia en él, que se gestó en distintos niveles y momentos, como se puso de manifiesto en el artículo. Ese sentimiento de injusticia dio origen a una forma de rebelión en González Prieto, que tuvo su máxima expresión en la invitación que éste le hiciera a los "campesinos, obreros, estudiantes y profesionales", a crear un "ejército nacional de liberación", para hacer una revolución similar a la que había ocurrido en Cuba. De ese modo se abrió un nuevo capítulo en la vida de Roberto González Prieto, que resultará ser el definitivo.

\section{Referencias bibliográficas}

Acevedo Tarazona, Á. (2004). El símbolo de un Robin Hood vengador en el occidente colombiano, Estudios Humanísticos, 3.

Afanador, M.Á. (1993). Amnistías e indultos: la historia reciente 1948 - 1992. Bogotá: ESAP.

Alape, A. (1994). Tirofijo: los sueños y las montañas 1964 - 1984. Bogotá: Planeta.

Alape, A. (1994). Las vidas de Pedro Antonio Marín, Manuel Marulanda Vélez. Bogotá: Planeta.

Delgado Madroñero, J. (2011). El bandolerismo en el Valle del Cauca: 1946-1966. Cali: Gobernación del Valle del Cauca y Secretaría de Cultura.

Díaz Jaramillo, J.A. (2012). Si me asesinan vengadme. El gaitanismo en el imaginario de la nueva izquierda colombiana: el caso del MOEC y de Enero, Anuario Colombiano de Historia Social y Política, 42(2).

Hobsbawm, E. (1983). Rebeldes primitivos. Barcelona: Editorial Ariel.

Guzmán Campos, G. (1964). La violencia en Colombia, Tomo II. Bogotá: Tercer Mundo.

Guzmán Campos, G., Fals Borda, O. y Umaña Luna, E. (1963). La violencia en Colombia. Estudio de un proceso social. Tomo I. Bogotá: Tercer Mundo.

Franco Isaza, E. (1973). Las Guerrillas del Llano: Medellín: Ediciones Hombre Nuevo.

Moec 7 De Enero (1960). Resolución Política del MOEC 7 de Enero. S.e.

Moncada, A. (1963). Un aspecto de la violencia. Bogotá: Promotora Colombiana de Ediciones y Revistas.

Moore, B. (1989). La injusticia: bases sociales de la obediencia y la rebelión. México D.F: Universidad Nacional Autónoma de México,

Pabón Núñez, L. (1963). Tres intervenciones del doctor Lucio Pabón Núñez. Bogotá Imprenta Nacional.

Prado Delgado, V.E. (2010). Bandoleros: imágenes y crónicas. Ibagué: León Gráficas.

Ramírez Bacca, R. (2004). Formación y transformación de la cultura laboral cafetera en el siglo XX. Medellín: La Carreta Editores. 
Sánchez, G. y Meertens, D. (1983). Bandoleros, gamonales y campesinos. El caso de la violencia en Colombia. Bogotá: El Áncora Editores.

Sánchez, G. (1985). Ensayos de historia social y politica del siglo XX. Bogotá: El Áncora Editores. Villanueva Martínez, O. (2007). Guerrilleros y bandidos. Los alias de los apodos de la violencia en Colombia. Bogotá: Universidad Distrital Francisco José de Caldas.

Zuluaga, J. (1993). La metamorfosis de un guerrillero: de liberal a maoísta. Análisis Político, 18. Bogotá: Universidad Nacional de Colombia.

Colombia. Corte Suprema de Justicia. Sala de Casación Penal. Amnistía e indulto; Septiembre 23 de 1958. Magistrado ponente: Dr. Antonio Vicente Arenas. Gaceta judicial (Bogotá). Vol. 89, no. 2202 (Sep. 1958). p. 205-208.

Colombia. Corte Suprema de Justicia. Sala de Casación Penal. El beneficio de la amnistía; Noviembre 16 de 1960. Magistrado ponente: Dr. Angel Martín Vásquez A. Gaceta judicial (Bogotá). -- Vol. 94, no. 2233-2234 (Nov./Dic. 1960). -- p. 210-214.

Colombia. Corte Suprema de Justicia. Sala de Casación Penal. Indulto y amnistía. Todo asesinato es atroz aunque pueda en casos particulares, escapar a esta calificación; Diciembre 18 de 1958. Magistrado ponente: Dr. Luis Eduardo Mejía Jiménez. Gaceta judicial (Bogotá). Vol. 89, no. 2203-2205 (Oct./Dic. 1958). p. 625-626.

Colombia. Corte Suprema de Justicia. Sala de Casación Penal. El beneficio de amnistía; Noviembre 16 de 1960; Corte Suprema de Justicia. Sala de Casación Penal; magistrado ponente: Dr. Ángel Martín Vásquez. Gaceta judicial (Bogotá). Vol. 94, no. 2233-2234 (Nov./Dic. 1960). p. 210-214

Colombia. Corte Suprema de Justicia. Sala de Casación Penal. Homicidio y otros delitos: solicitud de amnistía; Noviembre 22 de 1960 / Corte Suprema de Justicia. Sala de Casación Penal; magistrado ponente: Dr. Primitivo Vergara Crespo. Gaceta judicial (Bogotá). -Vol. 94, no. 2233-2234 (Nov./Dic. 1960). -- p. 222-224.

Gaitán Mahecha, Bernardo, Régimen jurídico sobre amnistía e indulto en Colombia, Revista jurídica (Bogotá). -- No. 28 (Sep. 1960). -- p. 41-44.

Sánchez Gómez, Gonzalo, Raíces históricas de la amnistía en Colombia, en Centro de Investigaciones socio-jurídicas facultad de derecho (Bucaramanga). -- Vol. 2, no. 13 (Dic. 1984). p. 33-66 